\title{
Power and Resistance: Digital-Free Tourism in a Connected
}

\section{World}

\section{ABSTRACT}

Although digital-free tourism is growing in popularity, research in this area has not unpacked the complex power relations between humans and technology through a critical perspective. Building on Foucault's analysis of power and resistance, we theorized technology as disciplinary power and conducted a collaborative autoethnography to explore how individuals resist the dominant discourse. Through a reflexive account, we theorize digitalfree travel as a process of negotiating and rejecting the dominant discourse of technology, particularly through effective personal strategies of engaging in full disconnection, redefining punishments and rewards, recalling nostalgic memories, and constantly reflecting on embodied feelings and self-transformations in the power relations. Theoretically, this study contributes to understanding digital-free tourism through the lens of power and resistance; it also contributes to critical studies in technology and tourism. Methodologically, we emphasize the potential of applying collaborative autoethnography in analyzing embodied self-transformations. Practically, this study offers suggestions for digital-free tourism providers.

Keywords: Digital-Free Tourism, Autoethnography, Disciplinary Power, Resistance, Foucault 


\section{INTRODUCTION}

Technology has increasingly played a facilitating role in tourism (Navío-Marco, RuizGómez, and Sevilla-Sevilla 2018); however, the concept of digital-free tourism (DFT) has attracted increasing academic interest (e.g., Egger, Lei, and Wassler 2020; McKenna, Waizenegger, and Cai 2020; Li, Pearce, and Oktadiana 2020). Earlier DFT research explored anxieties when disconnecting (Paris et al. 2015) and how DFT is perceived in the media (Li, Pearce, and Low 2018). More recent research has explored emotions that travelers face during DFT (Cai, McKenna, and Waizenegger 2020), how disconnecting enables a reconnection with "real life" (Pawlowska-Legwand and Matoga 2020), and the motivations for taking a digital detox (Egger, Lei, and Wassler 2020; Jiang and Balaji 2021). Travelling digital-free can be a test of coping skills (Rosenberg 2019) and building character strength (Li, Pearce, and Oktadiana 2020). However, barriers to taking a digital-free holiday exist, for example, personal and professional commitments (McKenna, Waizenegger, and Cai 2020) or nomophobia (the fear of not having a mobile phone), and fear of missing out (Floros et al. 2021). However, the complex and dynamic power relationship between digital technologies and tourists is neglected when discussing DFT. In addition, DFT is yet to be understood as a form of resistance towards the dominating discourse.

Research is yet to explore the embodied experience of how individuals negotiate their relationships with technologies in digital detox holidays. As a countercultural movement (Rauch 2018) to challenge dominant norms of technology, digital detox in tourism studies should engage in critical theories not only to advance the theoretical foundation of DFT but also contribute to wider discussions of power, surveillance, and technologies in the field of information technology and tourism studies (Cai et al. 2020). Not only should we understand DFT from a provider or society level, but it is also important to understand how individuals 
navigate and reflect on their tourist experiences when they decide to participate in DFT. Therefore, an autoethnographic approach allows us as researchers and participants of DFT to create deep analytical insights. To critically explore how power is exercised and resisted, this study is built on Foucault's analysis of power and resistance through a collaborative autoethnographic approach (Chang, Ngunjiri, and Hernandez 2016). The research question of this study is: how do individuals (re)negotiate their relationship with technology in the process of resisting the disciplinary power of digital technology? This study aims to theorize DFT through the perspective of power and resistance and contributes to critical information technology and tourism research. We provide an embodied and reflexive perspective to understand how individuals leverage various strategies to resist and negotiate with the dominant discourse. 


\section{LITERATURE REVIEW}

To understand DFT through the theoretical lens of power and resistance, we firstly conceptualize digital technology as Foucault's notion of disciplinary power. We discuss how technology as an omnipresent disciplinary power is sustained through normalizing discourse and exercised in a tourism context and everyday lives. We then conceptualize DFT as resistance towards digital technology. The conceptualization is built on the interconnected and mutually constitutive relationship between power and resistance. Four forms of resistance are suggested to lay the theoretical and methodological foundation of this study.

\subsection{Digital Technology as Disciplinary Power}

Power is found everywhere in tourism (Cheong \& Miller, 2000), both at the individual level where tourists are interacting with others (see Farmaki and Kaniadakis 2020; Gao, Cohen, and Hanna 2020) and the institutional level that consists of a network of policymaking and industry (see Dredge 2006; Zhao and Timothy 2015). Foucault does not consider power as a commodity that is possessed by any individual or institution but as something that exists through exercising and circulating within a network of relations (Foucault, 1978, 1980). Foucault shifts the focus towards the dynamics of power relations in various localized settings where "power reaches into the very grain of individuals, touches their bodies and inserts itself into their actions and attitudes, their discourses, learning processes and everyday lives" (Brochier, 1980, p. 39). Foucault conceptualizes three forms of power in different historical phrases (Larsson, Letell, and Thörn 2012; Dean 2010): sovereign power (law-like regulations that limit, punish, and repress certain behaviors), disciplinary power (a system of knowledge that shapes norm, which is exercised by individuals), and biopower ("technologies of power" that govern the population with a goal to improve quality of life). 
In today's society, digital technology can be conceptualized both as a form of disciplinary power at an individual level (Lifková 2019) and a form of biopower at an institutional level (Hepworth 2019). Cheong and Miller (2000) suggest that agents and targets are required to be identified when investigating power relationships. Regarded as the subservient part in the power relations (Foucault, 1980), tourists are considered as the target in this study. The role of agents in this context is to deploy tactics to strengthen the power relations of digital technologies on holiday. Agents are public and private brokers that adopt new technologies, and others such as Instagram influencers, Uber drivers, and Airbnb hosts. We acknowledge that technology could also be an agent (e.g., when using actor-network theory), but in this study, we are taking the perspective that digital technology is a tool utilized by agents to exercise and sustain power relations. In this study, we investigate digital technology as a form of “disciplinary power”. Johnston (1991) perceives Foucault’s disciplinary power as a system of knowledge that produces and normalizes discourses, which influences individuals to think and act in a similar way (Foucault, 1977).

Digital technology in our society today is considered "by default" (GOV.UK 2013, 2017). Such naturalization and normalization of the digital results in a technocentric view of contemporary life, where digital technology is highly integrated and inseparable in the discussion of social relations, identities, and culture (Kuntsman and Miyake 2019; Van Dijck 2013). Leclercq-Vandelannoitte and Aroles (2020) explore technology and the concept of control societies (Deleuze 1992). They argue that new processes of digitally enabled control are becoming normalized, which has implications for privacy and surveillance. In the tourism context, with the advocation and normalization of digital technology, today's holidays are highly connected, digitalized, and "smart". At a destination level, the concept of 
“smartmentality" from Foucault's notion of power and governmentality has been discussed by Vanolo (2014) and Johnson et al. (2021). Technologies of power are leveraged as a discipline mechanism to influence and persuade individuals' behaviors and involvements in smart city construction and force a moral order to differentiate good and bad cities. At an individual level, boundaries between home and away, life and work are blurred. There is a growing trend for tourists to share their experiences online, to respond quickly (White and White 2007), and to utilize various digital technologies to support their holiday experiences (McKenna, Cai, and Tuunanen 2018). This trend is exacerbated by destinations and tour providers leveraging new technologies to engage with their customers (Villamediana, Küster, and Vila 2019).

In addition, the choice of positive words such as "smart", "connect", and "intelligent" reinforce the normalized dominant discourse of digital technology in society. In recent years, some studies have adopted a more critical approach to problematize the dominant neoliberal discourse of technology transformation in tourism (Rydzik and Kissoon 2021) and criticize the impersonal mass quantification of big data (Weaver 2021).

Disciplinary power, on the one hand, trains individuals through scientific discourses and advocates the benefits of norms; on the other hand, it punishes, educates, and marginalizes those defined as "abnormal" (Lilja and Vinthagen 2014). Using Foucault's concepts of governmentality and technologies of power, Andrade and Techatassanasoontorn (2021) coin the term digital enforcement, which creates inequality and reduces choices for those who may wish to live their lives offline. Off-grid individuals and digital illiterates are considered abnormal in this context and are disadvantaged. Although the benefits of digitalization in our society have been widely discussed, Hepworth (2019) argues that this 
"mandatory convenience" is not a choice. The power is omnipresent (Cheong and Miller, 2000); with an increasing number of service providers, governments, and research going digital, it is difficult for individuals to avoid various monitors and regulations created by such norms. In addition, the discourse of constant connectivity has led to negative issues such as fear of missing out (Przybylski et al. 2013), nomophobia (Yildirim and Correia 2015), and difficulties disconnecting from work (Mazmanian, Orlikowski, and Yates 2013).

However, in Foucault's understanding, power is not only "repressive" but also "productive". The concepts of "surveillance" and "gaze", originating from Bentham's Panopticon, explains the productive aspect of power. The Panopticon was designed by Jeremy Bentham in the $18^{\text {th }}$ century. With a central guard tower, the guard can see the prisoners, but the prisoners cannot see the guards. With the chance of being watched, the prisoners internalized their gaze and became their own overseers (Foucault, 1977). This centralized design produces an economy of power that transforms individuals actively in (re)producing and exercising power and results in reducing the cost of surveillance. In today's society, the disciplinary influence of surveillance afforded by digital technology (Humphreys 2011) is largely practiced by friends, families, and colleagues. Through various apps, we can see where our friends are, what they are doing, and how many steps they walk.

In a tourism context, Germann Molz (2006) argues that interactions between individuals are a form of self-discipline. With virtual audiences' surveillance gaze in mind, tourists are required to report their whereabouts and experiences constantly and regularly. Differing from the 18th-century state level of surveillance, people in this mini, networked, and interpersonal Panopticon are self-driven (Hepworth 2019). They voluntarily share and report their data online and receive joy through the process. Without notice, tourists and their 
networks actively strengthen the disciplinary power repeatedly. A recent documentary, Social Dilemma, has illustrated that through using social media and engaging with social surveillance, individuals are not only points of powers' application (Foucault, 1980) but also have been regarded and transformed as productive and effective instruments by disciplinary power (Foucault, 1977) for other interests and agenda. A study exploring the use of wearable technologies using Foucault's metaphor of the Panopticon found that they can be both empowering (e.g., personalized recommendations, safeguarding users, or encourage healthy behaviors) and disempowering (e.g., users describe themselves only as numbers and become objects instead of subjects in conversation) (De Moya and Pallud 2020).

\subsection{Resistance towards Disciplinary Power}

"Where there is power, there is resistance" (Foucault 1978, 95-96). The interconnected and entangled relationship between power and resistance has been emphasized (Paddison et al. 2002). Lilja and Vinthagen (2014) further emphasize these two concepts are not necessarily opposed but mutually constitutive. Resistance can not only be considered as a reaction towards power relations but also reinforces existing power or creating new power relationships. As discussed earlier, disciplinary power is about producing a discursive norm and defining normal behavior through training, correcting, and punishing. Kuntsman and Miyake (2019) call for denaturalizing the link between digitality and sociality. The resistance towards such power can be conducted through passive forms of escape and avoidance such as non-institutional drifters and going off-grid, or positive forms of destabilizing controls or rearticulating discourses such as boycott and protest (Kannisto 2018; Scott 1990).

In communication and media studies, digital disconnections are considered a form of media resistance (Syvertsen and Enli 2020) and countercultural movements (Sutton 2020; 
Rauch 2018). By voluntarily withdrawing from social media platforms, participants demonstrate rebellion against the digitalization norm and are empowered by their own choices (Bucher 2020). Tribe and Mkono (2017) explore information and communication technologies in tourism as a discourse, and some travelers apply strategies such as limiting technology use or going off-grid as a form of resistance. However, most disconnection and non-use studies focus on withdrawing from certain social media (Brubaker, Ananny, and Crawford 2016) rather than digital technology as a whole.

Power and resistance in tourism studies have been investigated in understanding disabled individuals' resistance strategies (Eichhorn, Miller, and Tribe 2013); global nomad's resistance towards the industry (Kannisto 2018); alternative knowledge productions towards positivist and managerial studies (Tribe 2007; Franklin and Crang 2001); self-empowerment in the all-inclusive tours (Wang, Weaver, and Kwek 2016). Situated in power relations, these studies approach resistance as strategies, coping mechanisms, and alternative approaches responding to the dominating discourse. However, the conceptualization of resistances in these studies lacks a Foucauldian lens. Eichhorn et al. (2013) argue that the notion of resistance is investigated from both collective and individual levels. From the individual perspective, Wang et al. (2016) summed up active resistance, passive resistance, and nonresistance as self-empowerment strategies towards forced shopping in low-priced tour packages. Our study will be situated in the individual perspective to understand resistance.

Conceptualizing DFT as resistance is associated with the embodied turn, which builds on a feminist school of thought (Butler 1990) and performativity (Edensor 2001), and calls for a paradigmatic shift from the dominating "tourist gaze" visual discourse (Urry 1990) towards multisensory and gendered bodies in tourism writings (Johnston 2001). We argue 
that DFT as resistance should be understood as a process of embodied practices with a focus on reflecting sensory feelings and negotiating "doing" within the power relations. Focusing on disciplinary power, we thus conceptualize four forms of resistances through a Foucauldian lens.

Firstly, resistance can be achieved through overtly or covertly refusing to engage in practices that contribute to the exercises of power and normalize the subject. Lilja and Vinthagen (2014) suggest practicing this form of resistance can challenge the "discipline". This form of resistance is also informed by the "performance turn" (Haldrup and Larsen 2009), which shifts focus towards embodied doing and actions. Digital technology as disciplinary power has resulted in specific ways our body responded, such as muscle memories of scrolling and vibrations and the desire to unlock the screen unconsciously. Resisting towards this bodied familiarity could be challenging and resulted in various levels of withdrawal symptoms, but it can also be liberating and beneficial (Cai, McKenna, and Waizenegger 2020). Actively participating in digital detox, challenging the discourse of "smartmentality" and the norm of "connectivity", and advocating the benefits of digital minimalism can be considered as this form of resistance. In the context of DFT, we can understand the attempt to minimalize technology use or fully disconnect during the holiday intentionally as examples of this form of resistance.

The second form of resistance is "reversed" power or reverse discourse (Hartmann 2003; Weaver 2010). As power and resistance are entangled and interconnected, the same technologies of power (Nealon 2007) are leveraged through rearticulating and reiterating the dominating discourse with a different meaning (Butler 1995) or negotiating the punishment and reward, which will result in a different outcome (Lilja and Vinthagen, 2014). As a result, 
the dichotomy between normal and abnormal no longer exists. Foucault $(1978,101)$ explained how LGBT communities exercising reversed discourse as a form of resistance: "homosexuality began to speak in its own behalf, to demand that its legitimacy or 'naturality' be acknowledged, often in the same vocabulary, using the same categories by which it was medically disqualified”. Other examples such as Queer Youth (Tilsen and Nylund 2010), Asian comedians in the west (Weaver, 2010), and non-white women with low income (Little 1999), as targets in the power relationship in each localized context, utilize reverse discourse as strategies as a form of resistance to destabilizing the power relations. In the context of this study, the term "connection", which is a key vocabulary in the discourse of digital technology, can be leveraged as a reversed discourse in the digital detox, such as "disconnect to re-connect" or "connect with the present".

Thirdly, Medina (2011) suggests counter-memory as a form of Foucauldian resistance. The strategy of such resistance is to use techniques such as recalling the forgotten memories, voices, and experiences from the past to destabilize the dominant discourse. By referring to the original and primary source, it potentially leads to an alternative narrative through a counter-perspective of the present. Romanticism and nostalgia can be interpreted as a form of resistance towards the industrial and modern world. In the digital detox context, this form of resistance can be particularly powerful to millennials and generation X, who have memories of life without disruptive technology, and witnessed the significant changes in their lives and societies brought by digital technology. Syvertsen and Enli (2020) reflect on the time-space compression as a result of technological development in postmodern societies (Harvey 1999) and suggest digital detoxes represent a form of consuming authenticity and nostalgia when humans live harmoniously with time and space. 
Fourthly, in his later years, Foucault looks at the "technologies of the self" (Foucault, 1985, 1986), in which individuals engage with self-care and transforming themselves within the power relations (Rail and Harvey 1995). By shifting the focus on the self, technology of self can be considered as a form of resistance towards their subjectivity in the power relations. To leverage "technologies of the self" to transform themselves within power relations, individuals are required to be equipped with skills of problematizing the self and reflexivity (Foucault, 1984). Diaries are a form of "narratives of self" (Foucault, 1988) and play a crucial role in telling a reflexive personal story in the practice of freedom and transformation (Markula-Denison and Pringle 2007). This form of resistance legitimates the suitability of autoethnography as a method in this study. Collaborative autoethnography through diary writings will be conducted in this study to capture both the descriptive account of embodied, lived experiences in detail, and self-reflection during the shift of power relations in the various digital detox trips.

The conceptualization of digital technology as disciplinary power and the synthesis of four forms of resistance lays the theoretical and methodological foundations of this study. By theorizing digital technology as disciplinary power, we provided a critical perspective in understanding the omnipresent and dynamic nature of technology and the technocentric norm in society. Such norm is not only repressive through regulating and educating individuals and marginalizing those considered as "abnormal", but also productive through self-disciplinary mutual surveillance. In addition, we conceptualize DFT as a form of resistance towards such disciplinary power. This conceptualization is built on the entangled and mutually constitutive relationship between power and resistance. We further conceptualize four forms of resistance towards disciplinary power through a Foucauldian lens. The first three forms of resistances (refuse to engage in practices; reverse discourse; counter-memory) will offer a theoretical 
focus in the later stage of data analysis, the fourth form of resistance (technologies of self) informs the methodological choice of autoethnography. 


\section{RESEARCH METHODS}

This study used the autoethnographic method, advocated by Tussyadiah (2014) for tourism studies as a method of naturalistic inquiry to capture natural and real use situations. In recent years, the autoethnographic method has been adopted in tourism research (e.g., Buzinde 2020; Shepherd, Laven, and Shamma 2020; Wang, Weaver, and Kwek 2016; Magrizos, Kostopoulos, and Powers 2021). To understand resistance in power relations, autoethnography responds to Foucault's call for "technologies of the self" (Foucault, 1986) to engage in problematizing subjectivities and self-transformation through producing a personal, reflexive account. By producing both detailed, embodied descriptive accounts and in-depth, reflective analysis of the "self", authors in autoethnography "wrestle with the semantics of the body, including framing the body as self rather than as a property of the mind-self and portraying the body as fluid and changeable" (Ellingson 2006, 306). In particular, we used two specific versions of autoethnography, namely, collaborative autoethnography (Chang, Ngunjiri, and Hernandez 2016) and analytic autoethnography (Anderson 2006). Collaborative autoethnography has the benefit of allowing deeper understandings of the self than solo autoethnography, as researchers can interrogate each other's experiences (Chang, Ngunjiri, and Hernandez 2016). Using this approach allows us to bring together the autoethnographic data of the research team while also grounding the autoethnographic method in a theoretical approach.

\subsection{Autoethnography}

Autoethnography is a research method that describes and systematically analyses personal experiences to understand a socio-cultural experience and combines autobiography with ethnography (Ellis 2004; Ellis, Adams, and Bochner 2011). Because the experiences 
presented in this paper were internal feelings and very personal, the use of autoethnography is an appropriate method to explore resistance towards technology. Autoethnography empowers the personal life stories of the researcher, through the lens of the self, to gain an understanding of society (Chang 2008; Chang, Ngunjiri, and Hernandez 2016; Reed-Danahay 1997). There are two fundamental aspects of autoethnography: 1) the researcher uses autobiographical data: and 2) the data is interpreted as the connectivity between the researcher's self and others (Chang, Ngunjiri, and Hernandez 2016). Autoethnography allows the researchers to write their own experiences into the work; thus, enabling researchers' voices to be part of the findings (Holt 2003). The reader can then respond to this unique voice (Gergen and Gergen 2002) as it can more succinctly express the struggle of making sense of the experience (Boyle \& Parry, 2007), and personal stories have an impact that readers may relate to (Ellis and Bochner 2006). This is one of the advantages of autoethnography, as authors can tap into their lived experiences and bodily sensations, which also aids in the development of research questions that explore the experiences of individuals within specific contexts (Chang, Ngunjiri, and Hernandez 2016). Just as it is important to do representative studies, it is also important to explore an individual's perspective, which allows for deeper understandings of tourism phenomena (Farkić and Kennell 2021). Therefore, this study takes the perspective of learning from the individual (Smith 2004).

There are some criticisms of autoethnography, such as lack of theoretical rigor compared with more traditional scientific approaches (Wall 2006). However, autoethnography can provide theoretical contributions through thick descriptions of experiences (Duncan 2004). Others have claimed that the use of the self is problematic (Sparkes 2000). But a counter argument is that autoethnographies enable the voice of insiders (the researcher) to be more true than that of an outsider (Reed-Danahay 1997). External 
validity has been questioned in autoethnography but others have argued it should not be judged in a traditional sense (Bochner 2000), and is not something autoethnographies seek to attain (Wall 2006). Autoethnographies do not seek generalizability, but readers can determine if a story speaks to them and their own experiences or the people they know (Ellis 2004).

There are two main types of autoethnography, evocative (Ellis and Bochner 2006) and analytic (Anderson 2006), which differ in how autoethnographic data is presented. Evocative autoethnography are not tested against theoretical propositions (Shepherd, Laven, and Shamma 2020), while analytic autoethnography strives for theoretical development, refinement, or extension (Anderson 2006). The analytic approach is more commonly used in tourism research (Shepherd, Laven, and Shamma 2020). While we do not argue one approach over the other, we have adopted the analytic approach in this study as our goal is to provide theoretical contributions towards the growing body of research related to DFT.

\subsection{Positionality of the Researchers}

This autoethnography was undertaken by Brad and Wenjie, both millennials. Brad is an information technology researcher and a self-confessed technology addict who has spent most of his academic career researching the social implications of technology use. Travelling digital-free was something he initially rejected as he considered technology to be an integral part of his life. The decision to disconnect came after he realized his technology use was becoming problematic. He was always looking at his phone and using social media at the cost of his personal relationships. For example, he was always "chasing likes" and would even delete social media posts that did not receive enough attention. Wenjie is a tourism academic with research interests in information technology and wellbeing. Wenjie was concerned about screen time in his personal and private lives. From 2016, he started to engage with various 
approaches to reduce his technology use, but also enjoys the benefits and convenience of digital technologies. Both Brad and Wenjie also discussed with each other how the nature of their work requires them to use technology, further motivating them to disconnect.

Brad and Wenjie have been travelling together since 2014. Until they decided to try DFT, they had been using technology during their travels, e.g., TripAdvisor to find restaurants, Google Maps to navigate, websites for ticket reservations, and social media to communicate with people back home. In 2016, after becoming aware of how embedded technology is in their holidays, they decided to explore how they can resist the power of technology, which informed the research question. The positionality of Brad and Wenjie has also influenced the knowledge production in this paper. By problematizing the 'self' in the power relations (Foucault, 1984), both Brad and Wenjie are aware of the dominating discourse of digital technologies and engage in the "technology of the self" to transform their subjectivities in the existing power relations (Foucault, 1982).

As Brad and Wenjie are both insiders (researchers) and users of digital technology, they can reflect on both their lived experience (as a user) and analytical insights (as a researcher) in creating their autoethnographic accounts. Neither Brad nor Wenjie grew up with digital technology but were introduced to it during their teenage years, so they can tap into their childhood memories and leverage the counter-memories during their power resistances. Brad and Wenjie have different levels of dependency on smartphones and intentions to digital detox, affecting how they negotiate with the disciplinary power of digital technology. For example, in Brad's daily life, he is often posting photos, chasing likes, and uses notifications as motivation to reinforce this behavior. He is aware of this, so he can tap 
into this to help him to understand how he can resist the tactics embedded in technology that entices users to maintain this behavior.

\subsection{Study Approach}

We used concurrent collaboration where we engaged in the research progress detailed below together, enabling us to have our own experiences but then to share our notes and stories through conversations with each other (Chang, Ngunjiri, and Hernandez 2016). We conducted our autoethnography over four separate trips over four years, during which we wrote diaries of our thoughts, feelings, and emotions while travelling digitally free. We travelled together for all four trips but wrote our diaries individually. Throughout each journey, we discussed with each other our thoughts, feelings, and emotions noted in our dairies.

Our first collaborative autoethnography began on 23 July 2016 with a day trip to Ely, UK. This trip was intended to be a trial disconnect experience, and we returned home at the end of the day. The second trip on 6 September 2016 was a trip to Vienna, Austria. We disconnected our phones before leaving home, and we remained disconnected for three days. On the fourth day, we turned our phones back on (because it was Brad's birthday) and continued the trip for another two days while connected. The next two trips took place during the COVID-19 pandemic. On 19 July 2020, we travelled to a remote cabin in a forest location near Saffron Walden, UK. The cabin has a disconnect concept where visitors lock their phone away in a box until the end of the stay. We stayed for three nights in this cabin. The final trip on 28 August 2020 was to the Lake District, UK. We drove there and stayed for seven nights in a cottage near Grasmere. 
For the first three trips, we fully disconnected. For the final trip, we used various combinations of disconnections. For example, on the first day, we turned off all social media notifications but allowed ourselves to use Google Maps for navigation. On the second day, we attempted to limit our social media use to an hour in the morning and an hour in the evening and fully disconnected during the day. On the third day, Brad left his phone in the cabin while Wenjie continued full use of his phone during the day. On the fourth day, Wenjie left his phone behind while Brad continued full use of his phone. For the remaining days of the holiday, we were fully connected.

Throughout these four trips, we shared our opinions and feelings. Each of us kept a detailed diary, which we wrote at the end of each day to capture our experiences. On some occasions, we wrote multiple times during the day, for example, when sitting beside a lake or in a café. In total, we wrote in eight pocket sized notebooks. According to Ellis (2004), “there is nothing more theoretical or analytic than a good story" (p. 194) and "when people tell their stories, they employ analytic techniques to interpret their world" (p. 195-196). In autoethnography, data interpretation and analysis is part of the writing process because researchers decide which stories to tell (Chang, Ngunjiri, and Hernandez 2016). Therefore, our writing and analysis activities were heavily intertwined. We read our diaries to each other every day, which stimulated more discussion and theoretical thoughts. We noted these thoughts alongside our diaries and tagged text we thought was relevant against the theoretical backdrop. We then reflected further and noted down additional thoughts in our diaries. Together, we discussed the dominant discourse of digital technologies and the four forms of resistance we presented in the literature review. At all stages, we constantly self-reflected on ourselves as a "digital detoxer" through re-reading and discussing our reflexive diaries. To ensure trustworthiness (Nowell et al. 2017), once returning from our trips, we individually 
read each other's diaries and coded them against the theoretical backdrop. We then discussed our codes with each other and aggregated common themes. This was an iterative process with continuous (re)reading and discussion until we arrived at the themes which are detailed in the next section. 


\section{OUR DIGITAL DETOX JOURNEY}

\subsection{The Winding Road of becoming a Digital Detoxer}

Problematizing our subjectivities in the power relations (Foucault, 1986) through recognizing digital technology's disciplines and rules, we developed various strategies to manage the relationship with our smartphones throughout the collaborative autoethnography to seek the "ultimate" balance for DFT. Some forms of resistance tended to be less extreme through claiming sufficient agency (Tribe and Mkono 2017) and engaged in partially disconnected strategies (4.1.1), whilst other forms of resistance involve overtly refusing the smartphone use by practicing full "cold turkey" (4.1.2). Through engaging in different levels of digital detox, this section responds to the form of resistance by refusing to partake in activities that exercise disciplinary power (Lilja and Vinthagen 2014). We also reflect on how we re-negotiated the punishments of disconnecting (4.2) and how disconnecting gave us memories from our earlier lives (4.3). Furthermore, in the reflexive accounts, we constantly reflected on our self-transformational experiences as a digital detoxer and our negotiations, "battles", and resistance towards the discourse of digital technology. Such accounts of narrowing the negotiating process of problematizing and transforming the self in the power relations reflect the resistance of "technologies of the self" (Foucault, 1985, 1986).

\subsubsection{Partial disconnect: Technology: 1-Human:0}

On the first day in the Lake District, we went on a hike and turned all our notifications off but took our phones with us for navigation purposes. However, Brad found it rather challenging: 
I had to open my iPhone and go to the settings page and manually scroll through each app on my phone and turn notifications off manually one by one. I found this very, very, very frustrating. I have too many apps. I have to decide one by one if this app counts as social media. I can't express how much this annoyed me. I thought to myself, why is there not just one button you can click to turn all social media off? I also included emails in this task.

Although Brad attempted to turn off notifications to claim sufficient agency (Giddens 1979) with phone use, he already encountered difficulties negotiating alternatives with the disciplinary power of digital technology. Wenjie still received notifications, which reminded him of the omnipresence of digital technology:

Although I switched off notifications from my email and social media apps, I still received notifications from other apps, such as news, weather, meditations. When I used the phone for Google Maps, I saw these notifications, and that reminded me I am using the smartphone, and I am still sort of "connected" on a digital-free holiday. I don't particularly like this feeling. I did not achieve much by just turning off social and work apps. The existence of the mobile phone constantly reminding me that I am still connected one way or the other. It reminds me people can still reach out to me and that I can turn on the app so easily.

Brad also received news notifications, which led to some level of irritation: "During the day I did receive some notifications from apps which I had not turned off notifications for, such as the BBC news. For some reason, this annoyed me, and I thought next time I should also include news apps" 
Both Wenjie and Brad turned off notifications from communication apps aiming to achieve a sense of autonomy (Allen 2011) by reworking and negotiating the power relations with technology. However, their strategies were not effective in facing the powerful, persuasive discourse of digital technology. Both Wenjie and Brad made several mistakes by accidentally opening social media apps and realized afterwards:

During lunch, I opened Google Maps so that I could see where on the map we were. Since I do like maps generally, I often like to see where I am situated. While doing this, I accidentally opened Twitter without realizing. I began scrolling through Twitter and then suddenly realized, oh crap, and then closed it again. I told Wenjie what happened and how it is just sort of automatic; my fingers automatically go to Twitter when I look at my phone. I think my fingers have some sort of autopilot. It turns out Wenjie had automatically opened some apps too, so I didn't feel so bad about doing it (Brad).

Wenjie developed a sense of guilt and questioned the current strategy of resistance: "is using Google Maps really worth it? It is certainly useful guiding the route, but it also creates lots of anxiety, a sense of guilt, and not really feeling free from the connected world". On the second day, Brad came back with a new negotiation strategy of resistance by using notifications as warning signs:

We made quite a few stops along the way to take photos as the route was very scenic and beautiful. Each time I took my phone out to take photos, I noticed the red notification symbols, but this time, they worked as a warning not to open the app. The day before, I opened them without thinking even though there was no notification symbol on the app 
icon, but this time was different. Perhaps because the notification symbol was red, it acted like a stop sign or warning not to open the app. During my daily life, I would open the app when I had a new notification, but this time it didn't bother me, and it actually helped me not to open the app. I don't really know why, but my guess is that subconsciously I knew I wasn't supposed to be using the phone, and the red symbol acted as a stop sign, and I accepted it without a second thought. During the day, I never once opened up an app accidentally like I did before, even for emails, and I am usually addicted to emails!

During this trip, knowing they would, to some level, still use their smartphones, Wenjie purposely limited time for smartphone use for social purposes. Regardless of these rules, Wenjie still failed to break free from the Panopticon and ended up being the vehicle of power (Foucault, 1980) by reproducing and exercising the discourse. In his reflection, he noted how "hungry" they were after a whole day not checking social media: "when we got back, both of us are having a 'time to use social media' moment. As we didn't really check on our social media for the whole day, this is the time we can do it. But I noticed that humans are terrible at self-discipline. We started to put on different excuses to use social media a bit longer or setting up more ambiguous rules. In the end, I don't think we can get any 'freshness' out of this, but more a sense of guilt". A few days later, the rule was pushed, and the sense of guilt became weaker:

I started to find myself getting more and more relaxed about the rules I set. For the first two days, when I noticed I started to scroll through social media or emails, I developed a sense of guilt and will turn off the app immediately, but the feeling is getting weaker. 
Today, when noticing I accidentally opened my WeChat, I didn't lock the phone; instead, I stayed a bit and browsed the content of my WeChat.

\subsubsection{Full cold turkey: Human: 1-Technology: 0}

Differing from other forms of countercultural movements which involve collective behavior (Haenfler 2013), it could be challenging to achieve effective results of resistance when practicing at an individual level. Going full cold turkey was not easy at first. In our first digital detox to Ely, Brad left his phone at home but became more aware of his empty pocket where the phone usually sits: "I found during the day I kept subconsciously touching my pocket where I usually keep my phone and then remembering I don't have it. I realized that I never touch the pocket where I keep my wallet, so I value my phone more than my wallet, which I find a bit upsetting". This could be viewed as a withdrawal symptom from disconnecting (Cai, McKenna, and Waizenegger 2020) because the human body affects how technology is interpreted (Chughtai 2021). This demonstrated how just the embodied feeling of the phone's weight in his pocket meant a lot to Brad and caused him to reflect further on the disciplinary power his phone has over him. Wenjie also reported the embodied feeling of the smartphone's weight. However, Wenjie found that not feeling the weight of the phone was like taking the burden and stress off his shoulders. On the second detox trip to Vienna, Brad tried to negotiate these feelings. This time, he took his phone with him but turned it off. He noted, "I left my phone in my pocket this time because last time it was unnerving when I tapped an empty pocket." In this case, the disciplinary power of digital technology has trained the muscle memories of Brad's body, so he used the weight of the phone as a negotiating strategy. 
On the second day in Lake District, after struggling to find a fine balance of "not so successfully" reducing smartphone use the day before, we tried a more radical resistance by going full cold turkey. Brad's perspectives also began to change:

Today, we decided that I am going to leave my mobile phone in the cottage, and Wenjie will bring his. I was a bit stressed at the beginning, but after I made up my mind and left my phone behind, I felt rather relaxed during the whole day. There were some moments when Wenjie tried to show me some stuff on his phone screen, but I refused as I decided to be quite strict about phone usage on this day. I thought back to the earlier days on this trip where I had kept my phone on but turned notifications off. Being completely phonefree feels like a weight has been lifted. Although Wenjie had his phone, I just looked away when I noticed him using it.

Wenjie also noticed the positive changes in Brad during the day. In comparison, having the phone with him on the day, Wenjie found it rather stressful: "I can feel his whole energy changed during the day, he is much more laid back, relaxed. But for me, I feel a bit more stressed, as I am the only person taking charge of our navigations, information gathering etc.".

On the next day, it was Wenjie's turn to try full cold turkey:

I left my phone behind today. The feeling was brilliant! I don't need to worry about accidentally opening social media apps or checking emails without notice. I don't even need to worry that I have a phone with me, and I need to resist using it. It felt like I was set free from the cage, and I can truly enjoy the beautiful nature around me. 
Smartphones have the ability to disempower leisure time (Harmon and Duffy 2021), so Wenjie mostly enjoyed the day without his phone. However, the disciplinary power of the omnipresent connectivity (Kirillova and Wang 2016) from his phone still found its way to haunt Wenjie:

However, there are moments that we have to rely on Brad's Google Maps to figure out the routes. I was keen to check the map on his phone but realized I was supposed to be completely phone-free today. The existence of the phone (not even mine) is just like the Lord of the Rings - it kept tempting me! That is terrible! I need to resist it!

Understood as a countercultural movement (Rauch, 2018), digital detox links with the rebellion towards the mainstream discourse of digital technology. To resist the omnipresent disciplinary power of digital technology, we found the overt resistance (Kannisto 2018) by going full cold turkey is more effective than other covert, more subtle strategies.

Nevertheless, the process of resistance through leveraging various (un)successful negotiating strategies or refusals shape the subjectivities (Foucault, 1982) and identities of the digital detoxer. Practicing Foucault (1988)'s notion of the "techniques of the self", both Wenjie and Brad were determined to transform their existing subjectivities in a highly connected world by partaking and experimenting with various forms of resistance.

\section{2. (Re)negotiate rewards and punishments}

During their trip to the farm near Saffron Walden, Brad re-negotiated the rewards and punishments of using a paper map to replace Google Maps: 
I really enjoy using a paper map. I can look at it for hours and think of routes to travel and trying to interpret what the map features mean. Being able to find your position on the map without the blue dot of Google Maps is very exciting. It makes me feel more present and connected to my surroundings because it was through the constant (re)reading of the map and looking around for landmarks that enabled me to position ourselves. I think it requires some skill that may be lost to some people. We all use maps on our phone, but do we really "know" how to actually use a map? It is also a different feeling holding a physical map as you walk along - I can feel the pressure of the map against my fingers. While walking, I refold the map but have my finger inside it so I can quickly find our last location again when I unfold the map. I feel a strong sense of accomplishment when we arrived at the destination without not taking a single wrong turn.

In the reflexive accounts above, Brad rearticulated the meaning of "connection" to engage with the reverse discourse (Foucault, 1978) to resist the dominant discourse of technology. Instead of considering disconnect from digital technology and not being able to use Google Maps as a punishment, Brad reiterated the notion of "connect" by emphasizing the sensual feelings in his fingertips, situated engagements with surroundings, and the connections to the presence. In addition, the reward of feeling accomplished builds character strengths during DFT (Li, Pearce, and Oktadiana 2020).

On the same trip, Wenjie also re-negotiated the punishment and reward for being unable to take photos: 
At some point, I wish I brought my camera to take photos of today's walk. It is such a shame I cannot record those beautiful sceneries. But soon after, I realize it is actually quite a relief that I don't need to take photos. For a normal trip, I probably would take hundreds of photos; when I get back to the cabin, I need to spend time selecting good ones, editing, and post on social media. The thought has already exhausted me. So, in the end, I am glad I don't need to take photos and enjoy myself more with nature.

At first glance, not being able to take photos and share on social media instantly can be considered a punishment imposed by the omnipresent power (Cheong and Miller 2000) of digital technology. However, in the above narrative, Wenjie managed to re-negotiate punishment and reward and perceived that not taking photos and posting them on social media during the trips was a moment of reward. Through negotiating with the prevailing norm of photo taking and sharing during the trip, Wenjie practiced Foucault (1978)'s reversed discourse in resistance towards technology as disciplinary power.

During the pandemic, Brad stayed up-to-date, checking COVID-19 news and daily figures:

For the past 6 months I became obsessed with checking the COVID-19 news and daily figures in the UK: number of cases, deaths, and hospitalizations. But towards the end of the trip, I decided to turn off my news notifications. I debated if I should do this or not as it leaves me less informed, so it did make me anxious thinking I won't know what is going on. But in the end, I felt quite relaxed. Walking among the mountains and lakes and not receiving COVID-19 updates made me forget what was going on around the world. I felt much more relaxed. 
Not being able to access these updates could be considered as a punishment and potentially lead to increased anxiety; however, Brad re-negotiated the punishment and perceived that leaving the COVID-19 news behind brought him a sense of relief and relaxation as high intensity and distressing news afforded by digital technologies has caused several mental health issues (Moghanibashi-Mansourieh 2020). The digital-free experience provided a parallel experience and a reversed discourse to escape a world that is flooded by COVID-19 related news and allowed Brad to enjoy a carefree moment.

\subsection{Memories}

Recalling memories from the past introduces a counter-perspective that destabilizes the order and expectations about the disciplinary power of digital technology:

Wenjie: Memories of my childhood keep appearing on this trip. Some fragment pieces of memories that I nearly forgot flood suddenly into my brain. For example, last evening, there were lots of summer flies in the cabin; it reminds me of my hometown, it used to have many moths flying on our balcony before a storm. It is such a random piece of memory, and I haven't thought about those moths for at least 15 years since I left home for university. I try to figure out why I thought of these distant memories. I guess because we are not that occupied by any digital distraction and have more headspace to think and reflect. And the pace we have in this cabin is more like what we have as a child.

Brad: Both of us have been thinking about our childhood-perhaps because when we were children, we didn't have phones. I started to think about a childhood song I used to sing: "If you go down to the woods today, you're sure of a big surprise..." but I forgot the other lines. We used to sing this in school; I think when I was about 5 years old. I 
started singing that line of the song to Wenjie. Thinking about it really made me remember my childhood when I had barely a care in the world! A part of me wishes we could go back to that carefree attitude.

Such engagements with forgotten nostalgic memories, not just recalling what, but also reflecting why and how, and the effects in the context of power relations with digital technologies form a force of resistance "to destabilize the epistemic status quo" (Medina, 2011 pp. 11). During the practice of remembering the forgotten, Wenjie re-connected writing diaries with a sense of slowness:

In the cabin, I feel we are staying in a parallel world. To be more precise, it is more like travelling back to the past. Just like now, writing a diary with a pen and a notebook. I forgot when was the last time I did that. "Typing" is way faster than writing, and I really struggled at the beginning when writing this diary. I found the "speed of my thought" is much faster than the speed of writing; instead, I find the speed of my typing matches more the speed of thought. But I also think, does the speed of typing change the way we think and act? Did we used to think this way? I realized the way my thoughts formed are quite different when I follow the pace of handwriting. Because the slower pace of handwriting gave me some space to think properly before noting these ideas down. We are living in a very noisy and instant world, chasing productivity all the time. But it has taken away so much beauty.

We used to write with a pen all the time, didn't we? My diary used to be my haven for keeping all my sentimental secrets, joyful moments, and random complaints before the storm of digital technologies "washed it away" and replaced it. I truly miss those good 
old days. Those days without smartphones. We used to stare at the sky and feel that summer is never-ending. We were used to properly devote our time to one thing without many distractions. When staying in the cabin, it seems those times have come back.

Through handwriting diaries, Wenjie was able to slow down the pace of thinking and engage with problematizing the self in the digitalized world. Through recognizing ourselves as subjects (Scheurich and McKenzie 2005), such reflections and development of counterdiscourse (Mills 2003) offer opportunities for individuals to negotiate with the dominant discourse and escape from the disciplinary power (Eichhorn, Miller, and Tribe 2013). In addition to valuing the slowness of handwriting, Wenjie also challenged the negative discourse of waiting. Instead, waiting during the digital-free experience is beautiful and therapeutic:

I experienced lots of moments of waiting. Waiting for coffee to grind, to brew, waiting for water to be boiled. Waiting for a polaroid photo to appear, waiting for the sun to set, the sky to turn dark, and the stars to appear. We are not used to this kind of waiting. In our daily lives, we are chasing efficiency, and instant results. We try our best to minimize the time between the action and the result. But here, in the digital detox cabin. I find the time of waiting is therapeutic. It is exciting, full of hope and expectations, and because we experience the time of waiting, we cherish the result more.

In the age of information overload, Wenjie treasured the moments of solitude and the connections with nature during the DFT: 
I have been laying on the bed and staring at the field and the sky for hours through the window. Gosh, when was the last time I spent time like this and appreciated a moment of solitary? I stare out of the window, looking at the changing shapes of the clouds. The wind blows across the crop field and fluctuated beautiful waves. Groups of birds taking off. The observations of these tiny changes in nature go on and on. You can say my mind is detoxing from digital technology, but to be fair, I rarely think about it anymore. These small yet beautiful moments just keep flowing into and fill up my mind. This also happened on our walk yesterday. We walked to the middle of nowhere, surrounded by golden, or half golden, half green crops. There are moments where I can only hear the wind, the sound of wheat touching each other, and see endless fields. The moment, I was there, and so was my mind, and nothing else.

Recalling such beautiful yet forgotten moments in our everyday connected lives are an important reflective process for us as human beings to (re)negotiates our relationship with nature and technology. In addition to reflecting internally, we also engaged in conversations and discussions relating to our childhood memories and times before disruptive technologies. Through recalling nostalgic childhood memories and romanticizing the old-time without disruptive technologies, Wenjie's narratives destabilize the digital technology's dominant discourse (Medina 2011) in our everyday lives and question the myth of productivity, as well as advocating the forgotten joys and their origins. Revisiting the meaning of happiness, focus, and dedication, such practices of reviving "counter-memories" resist the disciplinary norm of digital technology. In our autoethnographic accounts, the alternative narratives that appreciate slowness and solitude are considered as a form of resistance towards the hyperconnectivity and productivity imposed by the discursive norm of digital technology. 
In addition, through writings diaries without technology distractions, we paid attention to ourselves rather than technologies, which shifts the power relations to our subjectivities. Through ongoing "narratives of the self" (Foucault, 1988) in forms of self-reflection and conversations, as well as this autoethnography account, we constantly problematized and revisited our relationship (Foucault, 1984) with digital technologies. Such exercises as a practice of freedom and resistance (Markula-Denison and Pringle 2007) challenge the established power relations between technologies and humans. 


\section{CONCLUSION}

Foucault's notion of power is exercised and normalised through everyday encounters (Hollinshead 1999). This study conceptualized digital technologies in our everyday lives and holidays as disciplinary power. This study explored the process of resisting the discourse of digital technologies through minimizing or refusing technology use, re-negotiating punishments and rewards, and recalling nostalgic memories on digital detox holidays. Through the collaborative autoethnographic accounts, both authors reflected, discussed and criticized their relationships with technologies and transformed their subjectivities in the power relations (Foucault, 1988). Through self-empowerments (Wang, Weaver, and Kwek 2016) and the "technologies of the self" (Foucault 1988), individuals who are aware of power imbalances between digital technologies and human beings start taking actions to mitigate the negative influence on wellbeing. In this study, various strategies of resistance were leveraged to resist the omnipresent and disciplinary power of digital technology. Learning from several failed attempts to claim sufficient agency by minimizing smartphone use on holiday (Tribe and Mkono 2017), we found a more overt and extreme approach is more effective to resist the dominant discourse of digital technology. By going "cold turkey" when travelling, "mentally away" can be aligned with "physically away" (Floros et al. 2021). Before the era of digital technologies, travel used to be regarded as a means to escape from everyday lives; however, with the increasing adoption of digital technologies, the boundaries between holiday and everyday lives has blurred (White and White 2007). Acknowledging the challenges to disconnect in day-to-day life, DFT can be considered as a good way to reestablish the boundary between work and life, holidays, and mundane experiences. By going "cold turkey" in the DFT, individuals have the chance to reflect on the unbalanced power relations in the digitalized world, and potentially achieve a more balanced relationship with digital technologies after the trip. 
Four dimensions of resistance towards digital technologies were discussed in the findings. First, experimenting with the various extents of digital disconnection on holiday, we found disconnecting fully is a more effective form of resistance and more likely to reshape the power dynamics between digital technology and human beings. Second, reverse discourse (Foucault, 1978) and redefining punishments and rewards (Lilja and Vinthagen 2014) were applied to emphasize the benefits of digital detox holidays and problematize the dominant discourse of digital technologies. Through engaging and creating alternative narratives, individuals have the chance to imagine a parallel life without technologies and reflect on their current relationship. Third, through recalling nostalgic moments of childhood and romanticizing slowness and solitude during DFT, counter-discourse was introduced as a form of resistance to destabilizing the order of the disciplinary power (Medina 2011) by remembering the times without disruptive technologies. Fourth, "technologies of the self" are actively engaged by constantly reflecting on embodied feelings, emotions, and relationships with technologies, nature, self, and the past and present through autoethnographic diary writings and discussions. This led to transformations of subjectivities and shifts of power relationships as an outcome of resistance recorded in the collaborative autoethnography.

There are four theoretical contributions in this study. First, positioned in Foucault's notions of power and resistance, this study theorizes the concept of DFT as a process of negotiating and rejecting the dominant discourse of digital technology in a tourism context. In addition, by investigating the reflexive and negotiation journey, the study discusses how subjectivities had been reshaped and transformed in power relations through resistance. This resistance towards the disciplinary power at the individual level is transferable in 
investigating how individuals leverage various techniques to challenge and problematize the dominant discourse and engage in the transformation of self in various power relations in the tourism context. Second, this study conceptualizes the disciplinary power of digital technology in tourism, which contributes to the critical discussions of technology and tourism studies (Cai et al. 2020). Looking at digital technology through the Foucauldian lens invites new understandings of various levels of control, governance, power distributions, surveillance, and knowledge production in tourism studies. The omnipresent power dynamics in technology used in both micro and macro levels should be acknowledged and critically investigated. Third, contributing to the overlooked Foucauldian resistance studies, this is the first study in tourism to conceptualize and practice four forms of resistance towards disciplinary power. It offers a new theoretical understanding and future research roadmap to investigate counterculture, subculture, and niche tourism such as lifestyle travelers, nomads, and how these groups resist mainstream tourism. Fourth, this is the first tourism study to apply Foucault's notion of power and resistance within a collaborative analytical autoethnography. Through the in-depth analysis of the embodied narrative of the self, this method offering an insight into the process of rejecting, negotiating, and transforming in the dynamic power relations, which are difficult to obtain through other methods.

This study also generates some practical implications for stakeholders. Digital detox providers should engage in experience design focusing on maximizing wellbeing benefits. For instance, providing toolkits for guests to engage in self-reflection and mindfulness, creating spaces to re-connect with nature, activities to foster conversations, and designing experiences to stimulate senses and revive nostalgic memories. More guidelines and suggestions to help guests to transform the disconnecting punishment into re-connecting rewards are recommended. In addition, tourism providers should offer customized support to 
help guests remove barriers to disconnect. This is particularly important in pre-trip communications. Furthermore, Digital detox holiday providers should also extend the wellbeing agenda to the post-trip era and guide customers to implement what they learned in their digital-free trip to a more balanced digital wellbeing. In addition, destination management organizations should not only focus on advocating digitalization, but also cater for the increasing needs of DFT, which requires inclusive adjustments of the tourism facilities.

Two limitations are identified. First, the study site, which included rural areas, national parks, and two cities, were all within Europe. These destinations are all relatively familiar to us, but our experiences may have differed if we had travelled to non-European destinations. Therefore, future research can be situated in unfamiliar destinations. Another limitation is that part of this study took place during the pandemic. Therefore, some experiences, such as reading COVID-19 daily statistics, may differ in the long term. Future research can further explore Foucault's notions of resistance to examine various power dynamics in tourism, such as host and guest, local residents, and tourism providers. The resistance towards disciplinary power can also be discussed in contexts where groups or forms of tourism are marginalized or considered as a subculture to the mainstream discourse. Studies of resistance towards power can go beyond disciplinary power and explore Foucault's discussions on biopower and sovereign power. In addition, we call for more studies in the field of DFT. This includes applying more critical theoretical approaches (e.g., political views, social movements) to enhance the understandings of DFT; further investigating the challenges (e.g., constraints to disconnect; the potential downside of DFT) and wellbeing benefits through naturalistic inquiries; and how DMOs and tourism providers respond to the specific characteristics of DFT tourists. 


\section{REFERENCES}

Allen, Amy. 2011. "Foucault and the Politics of Our Selves." History of the Human Sciences 24 (4): 43-59.

Anderson, Leon. 2006. “Analytic Autoethnography.” Journal of Contemporary Ethnography 35 (4): 373-95. doi:10.1177/0891241605280449.

Andrade, Antonio Díaz, and Angsana A. Techatassanasoontorn. 2021. "Digital Enforcement: Rethinking the Pursuit of a Digitally-Enabled Society." Information Systems Journal 31: 184-97. doi:10.1111/isj.12306.

Bochner, Arthur P. 2000. “Criteria Against Ourselves.” Qualitative Inquiry 6 (2): 266-72. doi:10.1177/107780040000600209.

Boyle, Maree, and Ken Parry. 2007. "Telling the Whole Story: The Case for Organizational Autoethnography." Culture and Organization $13 \quad$ (3): 185-90. doi:10.1080/14759550701486480.

Brochier, J. 1980. “"Prison Talk: An Interview with Michel Foucault.” In Power/Knowledge: Selected Interview and Other Writings 1972-1977, edited by C Gordon, 37-54. New York: Pantheon Books.

Brubaker, Jed R, Mike Ananny, and Kate Crawford. 2016. "Departing Glances: A Sociotechnical Account of 'Leaving’Grindr.” New Media \& Society 18 (3): 373-90.

Bucher, Taina. 2020. "Nothing to Disconnect from? Being Singular Plural in an Age of Machine Learning." Media, Culture \& Society 42 (4): 610-17.

Butler, Judith. 1990. Gender Trouble: Feminism and the Subversion of Identity. New York: Routledge.

—. 1995. "Subjection, Resistance, Resignification: Between Freud and Foucault." In The Identity in Question, edited by John Rajchman, 229-50. New York: Routledge. 
Buzinde, Christine N. 2020. "Theoretical Linkages between Well-Being and Tourism: The Case of Self-Determination Theory and Spiritual Tourism." Annals of Tourism Research 83 (July): 102920. doi:10.1016/j.annals.2020.102920.

Cai, Wenjie, Brad McKenna, and Lena Waizenegger. 2020. "Turning It off: Emotions in Digital-Free Travel.” Journal of Travel Research 59 (5). SAGE Publications Sage CA: Los Angeles, CA: 909-27. doi:https://doi.org/10.1177/0047287519868314.

Cai, Wenjie, Brad McKenna, Philipp Wassler, and Nigel Williams. 2020. "Rethinking Knowledge Creation in Information Technology and Tourism." Journal of Travel Research, August, 0047287520946100. doi:10.1177/0047287520946100.

Chang, Heewon. 2008. Autoethnography as Method. Walnut Creek, CA: Left Coast Press, Inc.

Chang, Heewon, Faith Ngunjiri, and Kathy-Ann C. Hernandez. 2016. Collaborative Autoethnography. London, UK: Routledge.

Cheong, So-Min, and Marc L Miller. 2000. "Power and Tourism: A Foucauldian Observation." Annals of Tourism Research 27 (2): 371-90.

Chughtai, Hameed. 2021. "Taking the Human Body Seriously." European Journal of Information Systems $30 \quad$ (1). Taylor \& Francis: 46-68. doi:10.1080/0960085X.2020.1746202.

De Moya, Jean-François, and Jessie Pallud. 2020. "From Panopticon to Heautopticon: A New Form of Surveillance Introduced by Quantified-Self Practices.” Information Systems Journal 30 (6): 940-76. doi:10.1111/isj.12284.

Dean, Mitchell. 2010. Governmentality: Power and Rule in Modern Society. London: Sage. Deleuze, Gilles. 1992. "Postscript on the Societies of Control." October 59. The MIT Press: $3-7$.

Dredge, Dianne. 2006. "Policy Networks and the Local Organisation of Tourism." Tourism Management 27 (2): 269-80. 
Duncan, Margot. 2004. "Autoethnography: Critical Appreciation of an Emerging Art." International Journal of Qualitative Methods 3 (4): 28-39. doi:10.1177/160940690400300403.

Edensor, Tim. 2001. "Performing Tourism, Staging Tourism: (Re)Producing Tourist Space and Practice." Tourist Studies 1 (1). SAGE Publications: 59-81. doi:10.1177/146879760100100104.

Egger, Inta, Sut Ieng Lei, and Philipp Wassler. 2020. “Digital Free Tourism-An Exploratory Study of Tourist Motivations.” Tourism Management 79: 104098.

Eichhorn, Victoria, Graham Miller, and John Tribe. 2013. "Tourism: A Site of Resistance Strategies of Individuals with a Disability.” Annals of Tourism Research 43: 578-600.

Ellingson, Laura L. 2006. “Embodied Knowledge: Writing Researchers' Bodies Into Qualitative Health Research.” Qualitative Health Research 16 (2). SAGE Publications Inc: 298-310. doi:10.1177/1049732305281944.

Ellis, Carolyn. 2004. The Ethnographic I: A Methodological Novel about Autoethnography. Walnut Creek, CA: AltaMira Press.

Ellis, Carolyn, Tony E. Adams, and Arthur P. Bochner. 2011. “Autoethnography: An Overview." Historical Social Research $36 \quad$ (4): 273-90. doi:https://doi.org/10.12759/hsr.36.2011.4.273-290.

Ellis, Carolyn, and Arthur P. Bochner. 2006. “Analyzing Analytic Autoethnography: An Autopsy." Journal of Contemporary Ethnography 35 (4). SAGE Publications Inc: 42949. doi:10.1177/0891241606286979.

Farkić, Jelena, and James Kennell. 2021. “Consuming Dark Sites via Street Art: Murals at Chernobyl." Annals of Tourism Research 90 (September): 103256. doi:10.1016/j.annals.2021.103256. 
Farmaki, Anna, and Antonios Kaniadakis. 2020. "Power Dynamics in Peer-to-Peer Accommodation: Insights from Airbnb Hosts.” International Journal of Hospitality Management 89: 102571.

Floros, Christina, Wenjie Cai, Brad McKenna, and Dimah Ajeeb. 2021. "Imagine Being Offthe-Grid: Millennials' Perceptions of Digital-Free Travel." Journal of Sustainable Tourism 29 (5): 751-66. doi:https://doi.org/10.1080/09669582.2019.1675676.

Foucault, M. 1977. Discipline and Punish: The Birth of the Prison. New York: Vintage Books.

—. 1978. The History of Sexuality: An Introduction (Vol. I). New York: Pantheon.

—. 1980. "Two Lectures.” In Power/Knowledge: Selected Interview and Other Writings 1972-1977, edited by C Gordon, 79-108. New York: Pantheon Books.

— 1982. "The Subject and Power." Critical Inquiry 8 (4). The University of Chicago Press: 777-95. doi:10.1086/448181.

. 1984. "Interview: Polemics, Politics and Problematizations." In Foucault Reader, edited by P Rabinow. New York: Pantheon Books.

- 1985. The Use of Pleasure: The History of Sexuality, Volume II. London: Penguin Books.

- 1986. The Care of the Self: The History of Sexuality, Volume 3. New York: Pantheon.

—. 1988. "Technologies of the Self" Technologies of the Self: A Seminar with Michel Foucault.” In , edited by L Martin, H Gutman, and P Hutton, 16-49. Amherst: The University of Massachusetts Press.

Franklin, Adrian, and Mike Crang. 2001. "The Trouble with Tourism and Travel Theory?" Sage Publications Sage CA: Thousand Oaks, CA.

Gao, Xiongbin, Scott Cohen, and Paul Hanna. 2020. "Hitchhiking Travel in China: Gender, Agency and Vulnerability." Annals of Tourism Research 84: 103002. 
Gergen, Mary, and Kenneth Gergen. 2002. “Ethnographic Representation as Relationship.” In Ethnographically Speaking: Autoethnography, Literature, and Aesthetics, edited by Arthur P. Bochner and Carolyn Ellis, 11-33. Oxford: AltaMira Press.

Germann Molz, Jennie. 2006. “'Watch Us Wander': Mobile Surveillance and the Surveillance of Mobility." Environment and Planning A 38 (2): 377-93.

Giddens, Anthony. 1979. Central Problems in Social Theory: Action, Structure, and Contradiction in Social Analysis. Vol. 241. Univ of California Press.

GOV.UK. 2013. "Government Digital Strategy: Reports and Research." GOV.UK. https://www.gov.uk/government/collections/government-digital-strategy-reports-andresearch.

- 2017. "Government Transformation Strategy 2017 to 2020." GOV.UK. https://www.gov.uk/government/publications/government-transformation-strategy2017-to-2020.

Haenfler, Ross. 2013. “Countercultures.” In The Wiley-Blackwell Encyclopedia of Social and Political Movements. American $\quad$ Cancer doi:10.1002/9780470674871.wbespm056.

Haldrup, Michael, and Jonas Larsen. 2009. Tourism, Performance and the Everyday: Consuming the Orient. London: Routledge. doi:10.4324/9780203873939.

Harmon, Justin, and Lauren Duffy. 2021. "Alienation from Leisure: Smartphones and the Loss of Presence." Leisure/Loisir $\quad 0 \quad(0) . \quad$ Routledge: 1-21. doi:10.1080/14927713.2021.1886870.

Hartmann, John. 2003. "Power and Resistance in the Later Foucault." In Annual Meeting of the Foucault Circle, 1-11. Cleveland, OH: John Carroll University.

Harvey, D. 1999. “Time-Space Compression and the Postmodern Condition.” In Modernity: After Modernity, edited by Malcolm Waters, IV:98-118. London: Routledge. 
Hepworth, Katherine. 2019. "A Panopticon on My Wrist: The Biopower of Big Data Visualization for Wearables." Design and Culture 11 (3): 323-44.

Hollinshead, Keith. 1999. "Surveillance of the Worlds of Tourism: Foucault and the Eye-ofPower." Tourism Management 20 (1): 7-23.

Holt, Nicholas L. 2003. "Representation, Legitimation, and Autoethnography: An Autoethnographic Writing Story." International Journal of Qualitative Methods 2 (1): 18-28. doi:10.1177/160940690300200102.

Humphreys, Lee. 2011. “Who's Watching Whom? A Study of Interactive Technology and Surveillance.” Journal of Communication 61 (4). Oxford University Press: 575-95. Jiang, Yangyang, and MS Balaji. 2021. "Getting Unwired: What Drives Travellers to Take a Digital Detox Holiday?” Tourism Recreation Research. Taylor \& Francis, 1-17.

Johnson, Abbie-Gayle, Jillian M. Rickly, and Scott McCabe. 2021. "Smartmentality in Ljubljana." Annals of Tourism Research $86 \quad$ (January): 103094. doi:10.1016/j.annals.2020.103094.

Johnston, Deborah S. 1991. "Constructing the Periphery in Modern Global Politics." In The New International Political Economy, edited by C Murphy and R Tooze, 149-69. Colorado, CO: Lynne Rienner.

Johnston, Lynda. 2001. “(Other) Bodies and Tourism Studies.” Annals of Tourism Research 28 (1): 180-201. doi:10.1016/S0160-7383(00)00012-8.

Kannisto, Päivi. 2018. "Travelling like Locals: Market Resistance in Long-Term Travel." Tourism Management 67: 297-306.

Kirillova, Ksenia, and Dan Wang. 2016. "Smartphone (Dis)Connectedness and Vacation Recovery." Annals of Tourism Research 61 (November): 157-69. doi:10.1016/j.annals.2016.10.005. 
Kuntsman, Adi, and Esperanza Miyake. 2019. "The Paradox and Continuum of Digital Disengagement: Denaturalising Digital Sociality and Technological Connectivity.” Media, Culture \& Society 41 (6): 901-13.

Larsson, Bengt, Martin Letell, and Håkan Thörn. 2012. "Transformations of the Swedish Welfare State: Social Engineering, Governance and Governmentality." In Transformations of the Swedish Welfare State: From Social Engineering to Governance?, edited by Bengt Larsson, Martin Letell, and Håkan Thörn, 3-22. London: Palgrave Macmillan UK. doi:10.1057/9780230363953_1.

Leclercq-Vandelannoitte, Aurélie, and Jeremy Aroles. 2020. "Does the End Justify the Means?Information Systems and Control Society in the Age of Pandemics." European Journal of Information Systems, no. In Press (October): 1-16. doi:10.1080/0960085X.2020.1820912.

Li, Jing, Philip L. Pearce, and David Low. 2018. "Media Representation of Digital-Free Tourism: A Critical Discourse Analysis.” Tourism Management 69 (December): $317-$ 29.

Li, Jing, Philip L. Pearce, and Hera Oktadiana. 2020. "Can Digital-Free Tourism Build Character Strengths?" Annals of Tourism Research 85: 103037.

Lifková, Anna. 2019. "Digital Power: Self-Tracking Technologies through Michel Foucault Lens.” Politické Vedy 22 (4). Univerzita Mateja Bela: 81-101.

Lilja, Mona, and Stellan Vinthagen. 2014. "Sovereign Power, Disciplinary Power and Biopower: Resisting What Power with What Resistance?" Journal of Political Power 7 (1): 107-26.

Little, Deborah L. 1999. “Independent Workers, Dependable Mothers: Discourse, Resistance, and AFDC Workfare Programs." Social Politics: International Studies in Gender, State \& Society 6 (2): 161-202. 
Magrizos, Solon, Ioannis Kostopoulos, and Laura Powers. 2021. "Volunteer Tourism as a Transformative Experience: A Mixed Methods Empirical Study.” Journal of Travel Research 60 (4). SAGE Publications Inc: 878-95. doi:10.1177/0047287520913630.

Markula-Denison, Pirkko, and Richard Pringle. 2007. Foucault, Sport and Exercise: Power, Knowledge and Transforming the Self. London: Routledge.

Mazmanian, Melissa, Wanda J Orlikowski, and JoAnne Yates. 2013. "The Autonomy Paradox: The Implications of Mobile Email Devices for Knowledge Professionals." Organization Science 24 (5): 1337-57.

McKenna, Brad, Wenjie Cai, and Tuure Tuunanen. 2018. "Technology Enabled Information Services Use in Tourism: An Ethnographic Study of Chinese Backpackers." Pacific Asia Journal of the Association for Information Systems 10 (4): 37-64.

McKenna, Brad, Lena Waizenegger, and Wenjie Cai. 2020. "The Influence of Personal and Professional Commitments on Digitally Disconnected Experiences." In HumanCentric Computing in a Data-Driven Society, edited by David Kreps, Taro Komukai, T.V. Gopal, and Kaori Ishii, 305-314. Springer.

Medina, José. 2011. "Toward a Foucaultian Epistemology of Resistance: Counter-Memory, Epistemic Friction, and Guerrilla Pluralism.” Foucault Studies, 9-35.

Mills, Catherine. 2003. "Contesting the Political: Butler and Foucault on Power and Resistance.” Journal of Political Philosophy 11 (3): 253-72.

Moghanibashi-Mansourieh, Amir. 2020. “Assessing the Anxiety Level of Iranian General Population during COVID-19 Outbreak.” Asian Journal of Psychiatry 51: 102076.

Navío-Marco, Julio, Luis Manuel Ruiz-Gómez, and Claudia Sevilla-Sevilla. 2018. "Progress in Information Technology and Tourism Management: 30 Years on and 20 Years after the Internet - Revisiting Buhalis \& Law’s Landmark Study about ETourism.” Tourism Management 69 (December): 460-70. doi:10.1016/j.tourman.2018.06.002. 
Nealon, Jeffrey. 2007. Foucault beyond Foucault: Power and Its Intensifications since 1984. Redwood City, CA: Stanford University Press.

Nowell, Lorelli S., Jill M. Norris, Deborah E. White, and Nancy J. Moules. 2017. "Thematic Analysis: Striving to Meet the Trustworthiness Criteria." International Journal of Qualitative Methods 16 (1). SAGE Publications Inc: 1609406917733847. doi:10.1177/1609406917733847.

Paddison, Ronan, Chris Philo, Paul Routledge, and Joanne Sharp. 2002. Entanglements of Power: Geographies of Domination/Resistance. London: Routledge.

Paris, Cody Morris, Edward Alexander Berger, Simon Rubin, and Mallory Casson. 2015. "Disconnected and Unplugged: Experiences of Technology Induced Anxieties and Tensions While Traveling." In Information and Communication Technologies in Tourism 2015, edited by I. Tussyadiah and A. Inversini, 803-16. London: Springer.

Pawlowska-Legwand, Aneta, and \Lukasz Matoga. 2020. "Disconnect from the Digital World to Reconnect with the Real Life: An Analysis of the Potential for Development of Unplugged Tourism on the Example of Poland.” Tourism Planning \& Development, 124.

Przybylski, Andrew K, Kou Murayama, Cody R DeHaan, and Valerie Gladwell. 2013. "Motivational, Emotional, and Behavioral Correlates of Fear of Missing Out." Computers in Human Behavior 29 (4): 1841-48.

Rail, Genevieve, and Jean Harvey. 1995. "Body at Work: Michel Foucault and the Sociology of Sport.” Sociology of Sport Journal 12 (2): 164-79.

Rauch, Jennifer. 2018. Slow Media: Why Slow Is Satisfying, Sustainable, and Smart. Oxford University Press.

Reed-Danahay, Deborah. 1997. Auto/Ethnography. New York: Berg. 
Rosenberg, Hananel. 2019. “The 'Flashpacker' and the 'Unplugger': Cell Phone (Dis) Connection and the Backpacking Experience.” Mobile Media \& Communication 7 (1): $111-130$.

Rydzik, Agnieszka, and Chavan Sharma Kissoon. 2021. "Decent Work and Tourism Workers in the Age of Intelligent Automation and Digital Surveillance.” Journal of Sustainable Tourism 0 (0). Routledge: 1-18. doi:10.1080/09669582.2021.1928680.

Scheurich, J, and K McKenzie. 2005. "Foucault's Methodologies: Archaeology and Genealogy." In The Sage Handbook of Qualitative Research, edited by Norman K. Denzin and Yvonna Lincoln, 841-68.

Scott, James C. 1990. Domination and the Arts of Resistance: Hidden Transcripts. London: Yale university press.

Shepherd, Jack, Daniel Laven, and Linda Shamma. 2020. “Autoethnographic Journeys through Contested Spaces." Annals of Tourism Research 84 (September): 103004. doi:10.1016/j.annals.2020.103004.

Smith, Jonathan A. 2004. "Reflecting on the Development of Interpretative Phenomenological Analysis and Its Contribution to Qualitative Research in Psychology." Qualitative Research in Psychology 1 (1). Routledge: 39-54. doi:10.1191/1478088704qp004oa.

Sparkes, Andrew C. 2000. "Autoethnography and Narratives of Self: Reflections on Criteria in Action." Sociology of Sport Journal 17 (1): 21-43. doi:10.1123/ssj.17.1.21.

Sutton, Theodora. 2020. "Digital Harm and Addiction: An Anthropological View." Anthropology Today 36 (1): 17-22. doi:10.1111/1467-8322.12553.

Syvertsen, Trine, and Gunn Enli. 2020. "Digital Detox: Media Resistance and the Promise of Authenticity." Convergence 26 (5-6). SAGE Publications Ltd: 1269-83. doi:10.1177/1354856519847325. 
Tilsen, Julie, and David Nylund. 2010. "Homonormativity and Queer Youth Resistance: Reversing the Reverse Discourse." Counselling Ideologies: Queer Challenges to Heteronormativity, 93-104.

Tribe, John. 2007. "Critical Tourism: Rules and Resistance.” In The Critical Turn in Tourism Studies, edited by I Ateljevic, A Pritchard, and N Morgan, 29-40. London: Routledge. Tribe, John, and Muchazondida Mkono. 2017. "Not Such Smart Tourism? The Concept of eLienation." Annals of Tourism Research 66: 105-15.

Tussyadiah, Iis P. 2014. “Toward a Theoretical Foundation for Experience Design in Tourism.” Journal of Travel Research 53 (5). SAGE Publications Inc: 543-64. doi:10.1177/0047287513513172.

Urry, John. 1990. The Tourist Gaze: Leisure and Travel in Contemporary Societies. London: Sage.

Van Dijck, José. 2013. The Culture of Connectivity: A Critical History of Social Media. Oxford: Oxford University Press.

Vanolo, Alberto. 2014. "Smartmentality: The Smart City as Disciplinary Strategy." Urban Studies 51 (5). SAGE Publications Ltd: 883-98. doi:10.1177/0042098013494427.

Villamediana, Jenely, Inés Küster, and Natalia Vila. 2019. "Destination Engagement on Facebook: Time and Seasonality.” Annals of Tourism Research 79: 102747.

Wall, Sarah. 2006. “An Autoethnography on Learning About Autoethnography.” International Journal of Qualitative Methods 5 (2): 146-60. doi:10.1177/160940690600500205.

Wang, Ying, David B Weaver, and Anna Kwek. 2016. "Beyond the Mass Tourism Stereotype: Power and Empowerment in Chinese Tour Packages." Journal of Travel Research 55 (6). SAGE Publications Inc: 724-37. doi:10.1177/0047287515592971.

Weaver, Adam. 2021. "Tourism, Big Data, and a Crisis of Analysis." Annals of Tourism Research 88 (May): 103158. doi:10.1016/j.annals.2021.103158. 
Weaver, Simon. 2010. "The 'Other'Laughs Back: Humour and Resistance in Anti-Racist Comedy." Sociology 44 (1): 31-48.

White, Naomi Rosh, and Peter B White. 2007. "Home and Away: Tourists in a Connected World." Annals of Tourism Research 34 (1): 88-104.

Yildirim, Caglar, and Ana-Paula Correia. 2015. "Exploring the Dimensions of Nomophobia: Development and Validation of a Self-Reported Questionnaire." Computers in Human Behavior 49: 130-37.

Zhao, Shengnan Nancy, and Dallen J Timothy. 2015. “Governance of Red Tourism in China: Perspectives on Power and Guanxi." Tourism Management 46: 489-500. 